\title{
Effect of maternal weight on fetal outcome
}

\author{
Ushadevi $\mathbf{G}^{\mathbf{1}}$, Arul Anne Rose $\mathbf{S}^{2}$ \\ ${ }^{1}$ Dr Ushadevi Gopalan, Associate Professor, Department of Obstetrics and Gynecology, Tagore Medical College and \\ Hospital , Rathinamangalam, Chennai, India, ${ }^{2}$ Dr Arul Anne Rose S Associate Professor, Department of Obstetrics and \\ Gynecology, Tagore Medical College and Hospital, Rathinamangalam, Chennai-127. India
}

Address for Correspondence: Dr Ushadevi Gopalan, Associate Professor, Department of Obstetrics and Gynecology, Tagore medical college and hospital, Rathinamangalam, Chennai, E-mail: ushag7@ hotmail.com

\begin{abstract}
Introduction: Pregnancy in chronically undernourished women with low maternal weight results in delivery of low birth weight babies. Aim of the Study: our aim was to study the correlation between maternal weight during pregnancy with fetal outcome measured in terms of fetal weight and perinatal mortality. Materials and Methods: This was a hospital based prospective study conducted in the department of obstetrics and gynecology in our teaching medical college and hospital over a period of 2 years extending from Jan 2011 - Dec 2012. All the cases delivering in this hospital were taken for this study. Total of about 1449 cases were taken for this study. Results: In this study the average weight of patients was found to be $51.88 \pm 7.64 \mathrm{~kg}$. The mean birth weight was found to increase with increasing maternal weight. The difference in the mean birth weight was found to be statistically significant between the different groups $(\mathrm{P}<0.01)$ except between those patients with weight in range of 50-60 and those above $61 \mathrm{~kg}(\mathrm{P}>0.05)$. There was found to be a statistically significant increase in birth weight with increase in maternal third trimester weight from less than $45 \mathrm{~kg}$ to 55 $\mathrm{kg}$. Differences in perinatal mortality between these groups were found to be statistically insignificant $(\mathrm{P}>0.05)$. Conclusion: There was statistically significant increase in mean birth weight with increase in maternal weight upto 60 $\mathrm{kg}$. There was no correlation between perinatal mortality rate and maternal weight.
\end{abstract}

Keywords: Maternal weight, Birth weight, Perinatal mortality.

\section{Introduction}

The problem in India is compounded by the fact that being a developing country we will not be able to adopt the standards set by others in the west for comparative purposes or in the management of antenatal patients. So it becomes imperative that we study the various factors pertaining to the mother and the fetal outcome in this part of the country and try to set meaningful standards. In developing countries like India the nutritional status of women in the reproductive age group is not at all satisfactory. Their diets are deficient in calories and many other essential nutrients from early childhood to adulthood and their fertility rates are high. This long term nutritional deprivation results in poor body size of mother [1, 2]. Pregnancy in such undernourished mothers with low maternal weight and low dietary intake throughout the gestation often results in delivery of low birth weight baby.

Manuscript received: $4^{\text {th }}$ June 2015

Reviewed: $15^{\text {th }}$ June 2015

Author Corrected: $4^{\text {th }}$ July 2015

Accepted for Publication: $12^{\text {th }}$ July 2015
Low birth weight is one of the key reproductive health indicators whose outcome is influenced by consumption of reproductive health care. Rosenzweig and Schultz argue that one of the key measures of child health is that of birth weight [3]. Low birth weight is the single most important factor affecting infant morbidity and mortality [4]. However there is growing evidence that the adverse consequences of low birth weight continue throughout the life cycle [5].

"Birth weight" is the first weight of the fetus or infant obtained after birth and should be measured during the first hour after birth, before the appreciable postnatal loss of weight occurs [6] An adverse effect of low birth weight on neonatal, postnatal and infant mortality rate has been widely documented (ICMR Study) [7]. The relationship between pre pregnancy BMI and fetal growth is well known and that the smaller size women tend to have smaller babies [8]. It was concluded by Frederick et al that prepregnancy body mass index 
(BMI) and gestational weight gain influence infant birth weight and play significant roles in adverse pregnancy outcomes [9].

Inadequacy of nutritional status within reproductive age and pregnancy is an important health and nutritional problem among women and their children, which might bring undesirable consequences to reproductive health, as well as negatively contribute to child development, with reflections on birth conditions and morbimortality rates [10]. For reducing the prevalence of low birth weight, public health strategy needs to focus attention on better maternal nutrition [4].

\section{Aims and Objectives}

To study the correlation between maternal weights on fetal outcome measured in terms of fetal birth weight and perinatal mortality.

\section{Materials and Methods}

This was a hospital based prospective study conducted in the department of obstetrics and gynaecology in our teaching medical college and hospital over a period of 2 years extending from Jan 2011-Dec 2012. All the cases delivering in this hospital were taken for this study.
Total of about 1449 cases were taken for this study. The patients were from both rural and urban areas.

A detailed history including past and present history was taken from each patient and a thorough physical examination was done and basic investigations were done for all patients. The emphasis was on maternal weight. The weight of the mothers was taken before delivery at the time of entering into labour room. Weights were measured to the nearest half kilo and the scales were calibrated periodically.

The period of gestation was calculated from the first day of the last menstrual period, using the simple Naegle's rule and it was recorded in completed weeks. Confirmation of gestational age was done in all babies using Dubowitz score [11]. Assessments of babies were done within $48 \mathrm{hrs}$ after delivery. The babies were weighed naked within a few minutes of birth and the weights were recorded to the nearest 50 gms. All babies were followed up during their hospital stay and the presence of any neonatal problems including infections and neonatal outcome were noted. The data obtained were subjected to one way ANOVA using SPSS version 20.0 software. A posthoc tukey test was done to compare mean value between two different groups.

\section{Results}

Table 1: Relationship of maternal weight with mean birth weight and PNMR

\begin{tabular}{|c|c|c|c|c|c|c|}
\hline $\begin{array}{l}\text { Weight in kg just } \\
\text { before delivery }\end{array}$ & Number & Percentage & $\begin{array}{l}\text { Mean birth } \\
\text { weight }\end{array}$ & $P$ value & PNMR* & $P$ value \\
\hline$\leq 45$ & 163 & 11.25 & $2.335 \pm 0.588$ & \multirow{5}{*}{$\begin{array}{l}P<0.01 \\
P<0.01 \\
P<0.01 \\
P>0.05\end{array}$} & $7.98 \%$ & \multirow{5}{*}{$\begin{array}{l}P>0.05 \\
P>0.05 \\
P>0.05 \\
P>0.05\end{array}$} \\
\hline $46-50$ & 454 & 31.33 & $2.536 \pm 0.560$ & & $4.19 \%$ & \\
\hline $51-55$ & 503 & 34.71 & $2.638 \pm 0.527$ & & $2.19 \%$ & \\
\hline $56-60$ & 253 & 17.46 & $2.762 \pm 0.559$ & & $2.77 \%$ & \\
\hline$\geq 61$ & 76 & 5.24 & $2.894 \pm 0.547$ & & $2.63 \%$ & \\
\hline
\end{tabular}

* Perinatal mortality rate

Table-1 shows the relationship of maternal weight with mean birth weight and PNMR. In this study the average weight of patients was $51.88 \pm 7.64 \mathrm{~kg}$. Of the total 1449 patients, $11.25 \%$ were found to have weight less than $45 \mathrm{~kg}$, the weight was between $46-50 \mathrm{~kg}$ in 31.33 $\%$, the weight was between $51-55 \mathrm{~kg}$ in $34.71 \%$, the weight was between $56-60 \mathrm{~kg}$ in $17.46 \%$ of patients and weight more than $61 \mathrm{~kg}$ was found in $5.24 \%$ of cases.

The mean birth weight was found to increase with increasing maternal weight. The mean birth weight in those with third trimester weight less than $45 \mathrm{~kg}$ was $2.335 \pm 0.588$, while in those patients with weight between $46-50 \mathrm{~kg}$ it was found to be $2.536 \pm 0.560$ and in those patients whose weight was between $51-55 \mathrm{~kg}$ it was $2.638 \pm 0.527$. In patients with weight between 56$60 \mathrm{~kg}$ the mean birth weight was $2.762 \pm 0.559$ while in those with maternal weight more than $61 \mathrm{~kg}$, the mean birth weight was $2.894 \pm 0.547$. The difference in the mean birth weight was found to be statistically significant between the different groups $(\mathrm{P}<0.01)$ except between those patients with weight in range of 50-60 and those above $61 \mathrm{~kg}(\mathrm{P}>0.05)$. 
The increase in birth weight with increase in maternal weight from less than $45 \mathrm{~kg}$ to $55 \mathrm{~kg}$ was found to be statistically significant. With further increase in maternal weight there was no significant increase in mean birth weight.

In those patients with maternal weight less than $45 \mathrm{~kg}$, the perinatal mortality was $7.98 \%$, perinatal mortality was $4.19 \%$ in patients with maternal weight in the range of $46-50 \mathrm{~kg}$, in the range $51-55 \mathrm{~kg}$ perinatal mortality was $2.19 \%$, in the weight range of $56-60 \mathrm{~kg}$ perinatal mortality was $2.77 \%$ and in those with weight more than $61 \mathrm{~kg}$ perinatal mortality was found to be $2.63 \%$. However the difference in perinatal mortality between these various groups was found to be statistically insignificant $(\mathrm{P}>0.05)$

\section{Discussion}

Various maternal factors have varying degrees of influence on the ultimate outcome of the fetus in relation to its birth weight. The degree of influence each maternal factor has on intrauterine growth however varies. This prompted us to conduct a study on the influence of maternal weight on fetal outcome

The mean birth weight in this study was $2.61 \pm 0.58 \mathrm{~kg}$. As mentioned earlier these weights were obtained within an hour of delivery and hence the postnatal loss of weight did not account for any decrease in weight. Upto maternal weight of $55 \mathrm{~kg}$ there was a statistically significant increase in birth weight. There was no statistically significant increase in birth weight with increase in maternal weight beyond $56 \mathrm{~kg}$.

This study also corroborates that of Pachauri et al [12], Chhabra and Sharma [13] and Swain et al [14] who believe that the effect of maternal weight on the birth weight is very significant. Mukherjee and Sethna [15] reported a mean birth weight of 2654 gms in mothers weighing less than $45.5 \mathrm{~kg}$ and $2866 \mathrm{gms}$ in those weighing more than $45.5 \mathrm{~kg}$ while in our study the mean birth weight in those less than $45 \mathrm{~kg}$ group was $2.33 \mathrm{~kg}$ and in those weighing more than $45 \mathrm{~kg}$ was $2.72 \mathrm{~kg}$. Leela Raman [16] found that with increasing maternal weight, there is a shift to higher birth weight group especially above $3 \mathrm{~kg}$. In this study, difference in birth weights at the extremes of maternal weight was 660 gms.

Shah and Shah [17] found that birth weight of infant was low $(2.6 \mathrm{Kg})$ when the mother's weight was $40 \mathrm{~kg}$ or below at the $20^{\text {th }}$ week of pregnancy, but the mother weighing $50 \mathrm{~kg}$ or above at that period of pregnancy had delivered full term babies whose birth weight was high $(2.9 \mathrm{Kg})$

Contrary to our findings, North [18], Winikoff and Debrovner [19], Ash et al [20] found no association of maternal weight with birth weight of babies. However, their study population was derived from a largely middle class white background where maternal malnutrition was not a significant problem.

In our study there was a decrease in perinatal mortality rate with increasing maternal weight, but the difference was not found to be statistically significant. A significant increase in perinatal mortality was observed by Gopalan [21] where the maternal weight was $50 \mathrm{~kg}$ or less. In a national collaborative study by an ICMR task force, no consistent relationship was observed between maternal pregravid weight and neonatal morbidity [7].

Thus it is clear from the preceding discussions that many maternal factors are closely associated with birth weight of the offspring's and the perinatal mortality rate. The extent of influence a particular factor has on birth weight and perinatal mortality rate however has to be studied ideally with all other confounding factors controlled.

\section{Funding: Nil \\ Conflict of interest: Nil \\ Permission from IRB: Yes}

\section{References}

1. Lechtig A, Yarbrough C, Delgado H et al. Influence of maternal nutrition on birth weight. Am J Clin Nutr. 1975 Nov; 28(11):1223-33.

2. Bhatia BD, Tyagi NK. Maternal determinants of birth weight-A Multivariate analysis. Indian Pediatr.1984 May; 21(5):365-71.

3. Rosenzweig MR and Schultz TP. Estimating a Household Production Function: Heterogeneity, the Demand for Health Inputs, and their Effects on Birth Weight. Journal of Political Economy.1983; 91(5):72346.

4. Gagan Agarwal, Sartaj Ahmad, Kapil Goel, Vijay Kumar, Parul Goel, Meenal Garg and Ajay Punj. 
Maternal Risk Factors associated with Low Birth Weight Neonates in a Tertiary Care Hospital, Northern India .J Community Med Health Edu 2012, 2:177.doi: 10.4172/2161-0711.1000177.

5. Kogan MD. Social causes of low birth weight .J R Soc Med.1995; 88:611-15.

6. Valero De Bernabe J, Soriano T,Albaladejo R, Juarranz M, Calle ME ,et al. Risk factors for low birth weight: a review. Eur J Obstet Gynecol Reprod Biol. 2014:116:3-15.

7. Indian Council of Medical Research Task Force Study: A national collaborative study of identification of high risk families' mothers and outcome of their offspring's with particular reference to the problem of maternal nutrition, low birth weight, prenatal and infant morbidity in rural and urban slum communities, 1990.

8. United Nations Children's Fund and WHO, Low Birth weight: Country, regional and global estimates, INICEF, New York, 2004.Available online at: whqlibdoc.who.int/publications/2004/9280638327.pdf

9. Frederick IO, Williams MA, Sales AE, Martin DP, Killien M. Pre-pregnancy body mass index, gestational weight gain, and other maternal characteristics in relation to infant birth weight. Mat Child Health J, 2007

10. P.De Carvalho Padilha, E Accioly, C.Chagas, E Portela, CL Da Silva y, C.Saunders.Birth weight variation according to maternal characteristics and gestational weight gain in Brazilian women. Nutr Hosp.2009; 24(2):207-12.

11. Dubowitz LMS, Dubowitz V, Goldberg C. Clinical assessment of gestational age in the new born infant. J Pediatr .1970 Jul; 77(1):1-10
12. Pachauri S, Marwah SM. A Study of the effect of certain maternal factors on birth weight. Indian J Med Sci.1970 Oct; 24(10): 650-60.

13. Chhabra S, Sharma S.Variables affecting fetal weight. Indian J Matern Child Hlth.1994; 5:61-63.

14. Swain S, Bhatia BD, Pandey S et al .Maternal Biosocial and nutritional parameters and birth weight. Indian J Matern Child Hlth.1994; 5:68-72.

15. Mukherjee DK, Sethna NJ. Birth weight and its relation with certain maternal factors .Indian $\mathbf{J}$ Pediatr.1970; 37:460-64.

16. Leela Raman. Maternal Risk Factors in Intrauterine Malnutrition. Indian J pediatr.1987; 54(4): 503-10.

17. Shah KP, Shaw PM. Relation of maternal nutrition and low birth weight. Indian pediatr.1979; 16(11):961-6

18. North AF Jr. Small for date neonates. I. Maternal gestational and neonatal characteristics. Pediatrics.1966; 38: 1013.

19. Winikoff B, Debrovner CH. Anthropometric determinants of birth weight. Obstet Gynecol.1981; 58: 678-84.

20. Ash A, fisher CC, Tristwell As et al. Maternal weight gain, smoking and other factors in pregnancy as predictors of Infant birth weight in Sydney women. Aus NZ J Obstet Gynaecol.1989; 29:212-18.

21. Gopalan S. Identification and management of high risk pregnancies. Obstetrics and Gynecology for Postgraduates. Vol. I; Rathnam SS, Rao KB, Arulkumaran S, pg 9-18.

\section{How to cite this article?}

Ushadevi G, Arul Anne Rose S . Effect of maternal weight on fetal outcome. Int J Med Res Rev 2015;3(6):614-617. doi: 10.17511/ijmrr.2015.i6.119. 